\title{
Evaluación de la moneda alternativa como un medio que posibilita la economía solidaria: El caso de Suchitoto
}

\author{
Eduardo García Hernández, Karla Beatriz Escoto de Chavez, \\ Rolando Bustamante Estrada, Elmer Andrés Turcios Reyes \\ Universidad Centroamericana "José Simeón Cañas"
}

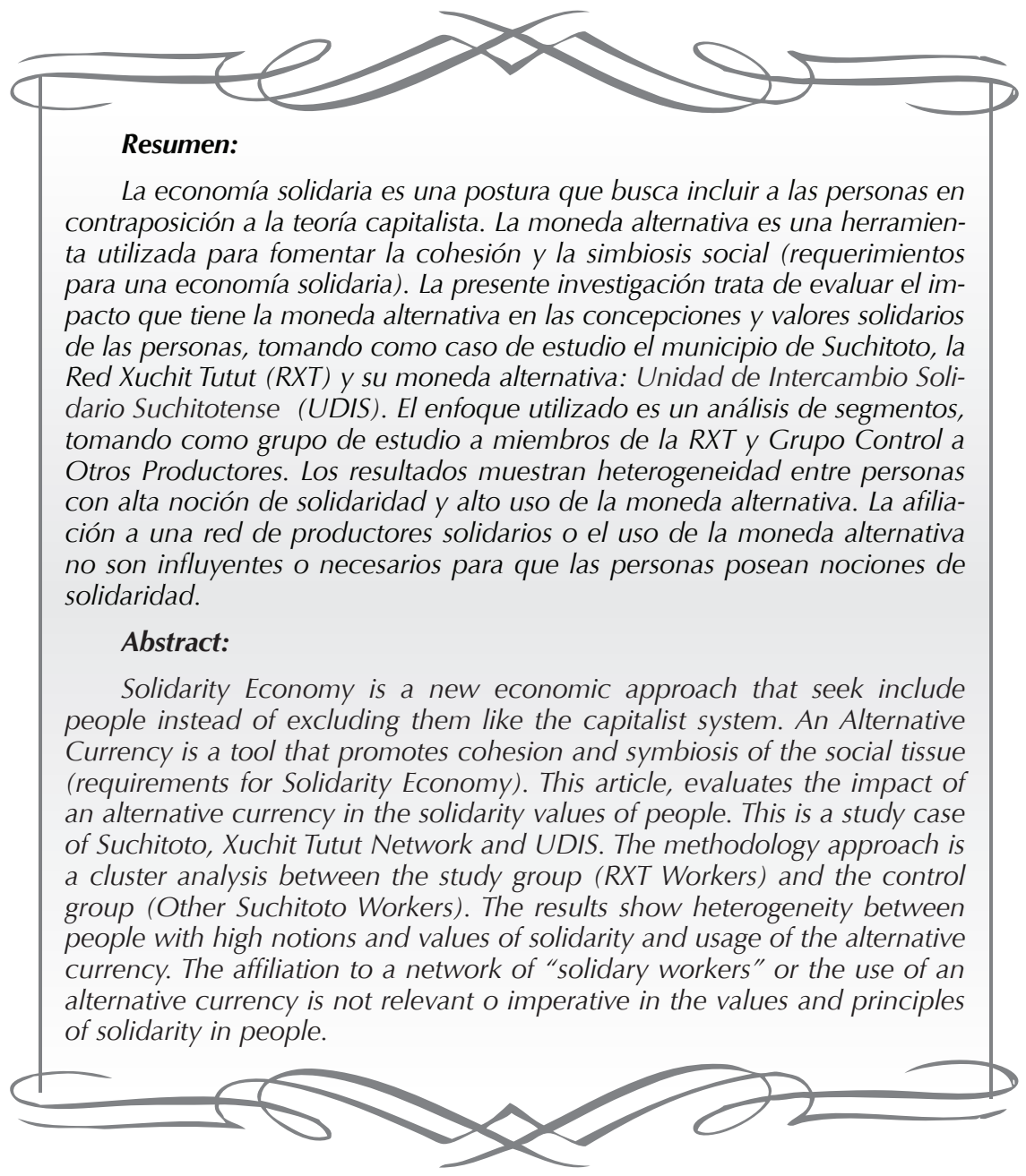




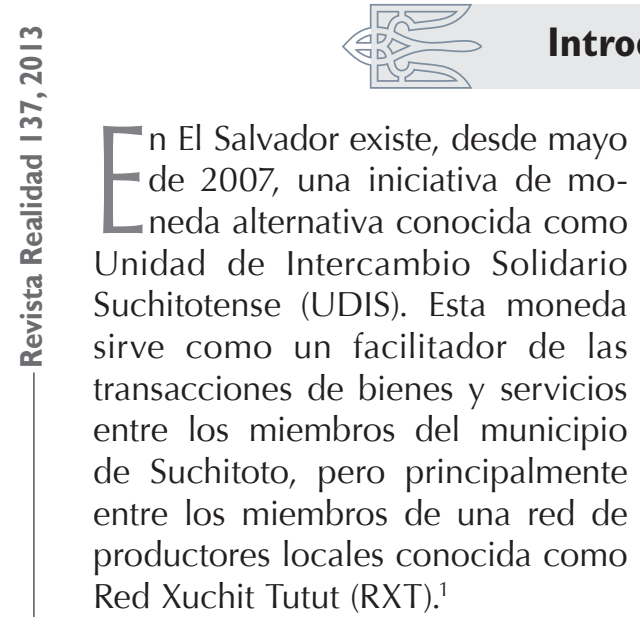

La RXT es una red conformada por 169 productores del municipio de Suchitoto. Fue esta red, junto con la ayuda de otras oenegés nacionales e internacionales, los promotores y emisores de los UDIS. El objetivo de la red es reactivar la economía suchitotense mediante la articulación de ofertantes y demandantes de bienes y servicios que actualmente han sido excluidos de la economía tradicional.

La exclusión de personas viene a través de insuficiencia de liquidez, por ejemplo: la falta de dinero en efectivo, créditos o préstamos para el consumo o la producción; personas sin dinero no son capaces de comprar bienes y carecen de medios para satisfacer sus necesidades básicas. La RXT busca eliminar esta causa de exclusión, a través de la utilización del UDIS para realizar transacciones de bienes y servicios. EI UDIS, como moneda alternativa, busca devolverle al dinero su carác- ter social y su carácter esencial: un medio que facilita el intercambio.

La teoría económica tras la RXT es la economía solidaria, la cual plantea la necesidad de las mayorías populares por procurar su autogestión, emancipación y participación económica, basándose en valores como la cooperación y la solidaridad. Además, busca resolver las causas que generan los problemas que azotan a las grandes mayorías.

Este artículo pretende mostrar el impacto que ha tenido la moneda alternativa UDIS en la masificación de valores y conductas propias de la economía solidaria en los miembros de la Red Xuchit Tutut y demás habitantes del municipio de Suchitoto. La forma de medición es a través de una evaluación a un grupo de miembros de la RXT y a un grupo de productores no afiliados a la red. Esta evaluación tratará de medir el comportamiento solidario a través de preguntas hipotéticas. Las respuestas serán ponderadas y se generará un indicador de solidaridad. Luego se pretende hacer un análisis de segmento para corroborar si existe una concentración de habitantes con un alto índice de solidaridad y otro de bajo índice. Se corroborará, en el caso existan estos grupos, si los usuarios de la RXT son predominantes en el grupo de mayor solidaridad. 
La importancia de este estudio radica en conocer el efecto que un medio exógeno (la moneda alternativa) tiene en la concepción económica de las personas, volviéndolas más propensas a actuar de manera solidaria o de manera competitiva.

El artículo se desglosa en cuatro partes: primero una parte introductoria, que aborda de manera general la teoría de economía solidaria, estudiada a través de Aquiles Montoya (UCA, 2005) y Luis Razeto (1993), la teoría acerca de las funciones del dinero (Dornbusch, Fischer, \& Startz, 2008) y de su origen (Marx, 1999) y, por último, termina abordando los conceptos básicos de la moneda alternativa (Plasencia
\& Orzi, 2007). La segunda parte abarca el método utilizado. La ficha técnica de la encuesta realizada, el objetivo de la misma, la creación del indicador de solidaridad y de percepción a la moneda alternativa y el método de segmentación two headed clusters. En la tercera parte, se muestran los resultados descriptivos de la encuesta, los resultados de los indicadores de solidaridad y percepción de moneda alternativa, y los segmentos obtenidos en el análisis. La última parte busca discutir acerca de los alcances que ha tenido la moneda alternativa en la RXT y en el municipio de Suchitoto, y determinar si se puede afirmar un efecto en la conciencia y las nociones solidarias de los habitantes.

\section{Economía solidaria}

El fundamento de la humanización está en la solidaridad y el fundamento de la economía en la satisfacción de las necesidades básicas Ignacio Ellacuría, S. J.
La economía solidaría se origina como una alternativa y una respuesta al sistema capitalista. Nace dentro del sistema capitalista como consecuencia de la exclusión, marginación y pobreza que condena a la mayoría de la población:

La economía solidaria se concibe como un modelo alternativo de y para las mayorías populares, en los ámbitos económico, social, político, cultural y ecológico, fundamentado en su propio esfuerzo organizativo y solidario, que tiene como finalidad resolver sus problemas ambientales, de pobreza y exclusión social, tanto en el campo como en la ciudad, y contribuir a la eliminación de las causas que los genera (Montoya \& Hernández, citados en UCA, 2005).

Es importante destacar que el objetivo de la economía solidaria es suplir las necesidades de los miembros de sus organizaciones, 
buscando la reproducción de sus vidas y mejorando la calidad de vida de los mismos; sin embargo, lo más importante y diferenciador de la economía solidaria con respecto a la tradicional es que busca eliminar las causas que generan los problemas. Es en las causas, en la eliminación de la raíz de los problemas, en donde la radicalidad de la economía solidaria florece. La economía tradicional busca atender los problemas, no obstante, omite sus causas.

Según Luis Razeto (1993), existen algunas características y elementos que le dan a la economía solidaria su distinción económica y cultural con respecto a la economía capitalista neoliberal. Parte de estos elementos son los siguientes:

1. Se desarrolla en los sectores populares de la sociedad.

2. Son iniciativas organizadas que suponen la formación de una estructura participativa en la que se toma decisiones colectivas sobre la actividad económica.

3. En la economía solidaria se logra una autonomía tras enfrentar sus problemas y necesidades mediante el propio esfuerzo, con la utilización de los recursos que se logran juntar.

4. Son iniciativas basadas en relaciones y valores solidarios.
5. Son organizaciones participativas, democráticas y autónomas, en tanto que los integrantes son los únicos Ilamados a tomar sus propias decisiones.

6. Buscan el excedente económi$\mathrm{co}$, pero no bajo una finalidad acumuladora, sino como un potenciador para su propia reproducción. La economía solidaria nace en un grupo pequeño $y$, a medida crece, todos los ingresos son reinvertidos para involucrar a más personas y eliminar la exclusión como relación económica latente.

En la economía solidaria se busca la generación de un excedente neto que posibilite la reproducción, creando nuevos puestos de trabajo y la satisfacción de las necesidades sociales; la mayor parte de las ganancias (o excedente) están destinadas a la reinversión. De esta forma, hay más recurso para incorporar a más gente a la actividad económica.

Es importante tener en cuenta la integración inter e intra sectorial dentro de estas iniciativas, ya que las diferentes unidades de la economía deben de integrarse para que exista un mayor alcance en los beneficios redistributivos de la actividad económica; aumentando los ingresos de sus miembros, se aumentará la demanda de bienes y servicios, traducida a un incremento de la producción. 
Esta alternativa económica se preocupa por la distribución de la riqueza, siendo ésta un fuerte eje en la actividad económica. Además, la economía solidaria reconoce un límite productivo y reconoce a la naturaleza como factor que debe ser reproducido y debe ser cuidado. Es la naturaleza el marco en el que podemos tener mejores niveles de vida.

\subsection{Funciones tradicionales de la moneda}

Para la economía capitalista neoliberal, lo esencial en el abordaje del dinero no es su esencia o su naturaleza, sino sus funciones; éstas son las que determinan al dinero. A continuación se exponen las funciones del dinero (Dornbusch et al., 2008).

\section{a) El dinero como medio de cambio.}

El dinero transformó el intercambio, haciéndolo más eficiente y superando el principal problema del sistema de trueque: la doble o múltiple coincidencia de deseos. En el trueque era necesario que los bienes que una persona vendiera fueran los mismos que otra persona deseara comprar y viceversa. Con el dinero se elimina este problema ya que al vender y obtener dinero, la persona está obteniendo un equivalente para cualquier otra mercancía que deseó y que esté disponible en el mercado. Es así como el dinero se vuelve un medio de cambio de productos.

Hay que hacer énfasis en la diferenciación del dinero como medio de cambio y como medio de pago. El dinero como medio de pago es usado para la cancelación de una deuda o algún compromiso que se adquiere -como una promesa de pago a futuro-, mientras que la función de medio de cambio se refiere a transacciones de compra y venta de mercancías (Plasencia \& Orzi, 2007).

\section{b) El dinero como unidad de cuenta}

El dinero como unidad de cuenta propicia un sistema de precios más simple y mejora la información del mercado, de esta manera se homogenizan los precios de los bienes y servicios. Esta función facilita a las personas la identificación del valor relativo de lo que se pretende adquirir o vender.

En pocas palabras, se puede homogenizar todas las mercancías y ponerle un precio o un número a éstas. El valor relativo de un bien o servicio es la cantidad de circulante que se está dispuesto a pagar y a recibir. Es por eso que los precios se pueden citar con unidades monetarias como el dólar, los centavos, los colones y los pesos. 


\section{c) El dinero como reserva de valor}

La función de reserva de valor del dinero en una economía capitalista es considerada una de las virtudes más grandes de este instrumento. Cuando las personas reciben dinero a cambio de bienes o servicios, no tienen que gastarlo inmediatamente porque el dinero puede mantener su valor en el tiempo. Lo utilizarán cuando sea necesario. Esto indica que puede conservar su valor nominal futuro e incorruptible. En cuanto a su valor real o capacidad adquisitiva, depende de otras condiciones y se representa mediante la inflación.

Esta función sería eficiente si con cierta cantidad de dinero se pudiera comprar la misma cantidad de bienes, tanto en el presente, como en el futuro. Si esto ocurriese, podríamos afirmar que el dinero cumple íntegramente su función de reserva de valor.

\section{d) El dinero como estándar de pago diferido}

Esta función del dinero no es exclusiva de éste. El dinero puede representar pagos en un futuro tras una transacción actual. Las compras a plazo de un carro representan un ejemplo de pago diferido, pues en esta transacción se da un pago hoy por recibir dinero en el futuro. Esta función se utiliza bastante en los mercados financieros en los cuales el dinero se paga a sí mismo en el tiempo, evitando que la inflación lo afecte. Un préstamo de dinero será pagado en el tiempo por más dinero nominal del que se recibió.

\section{e) Reflexiones sobre las funciones del dinero}

En el mundo real, los precios tienden a fluctuar y más concretamente tienden a fluctuar al alza. Esta subida de precios (inflación) hace que no se puedan comprar la misma cantidad de bienes con la misma cantidad de dinero en el tiempo. Esta realidad se debe a que el dinero, en su rol de reserva de valor, ha resultado deteriorado y ha perdido parcialmente su valor.

Por otro lado, se da el caso contrario, si los precios bajan (deflación) se puede comprar más cantidad de bienes con la misma cantidad de dinero en el futuro; en este caso podríamos decir que el dinero puede ganar valor con el tiempo. Esta ganancia no solo se da en la deflación, sino que puede provenir de muchos factores, uno de ellos la inversión con altas tasas de retorno. Esto se conoce como "poner a trabajar el dinero".

Godelier (1996) señala que la diferencia entre el sistema mercantil simple y el sistema capitalista es que este último emplea dinero como capital; por tanto, el dinero no solo se utiliza para comprar mercancías, sino también para generar 
ganancias. La inversión del capital permite la obtención de lucro y otros beneficios sin que haya trabajo directo del poseedor del dinero.

\subsection{La naturaleza del dinero desde la teoría marxista}

Marx explica cómo todas las mercancías pueden ser dinero, pero cómo solo una es aceptada como tal. La base del análisis marxista sobre el dinero se centra en la esencia del mismo, como una mercancía, y cómo ésta es socialmente designada como dinero.

El dinero, tradicionalmente, es considerado como un catalizador de la economía. Muchas veces se utiliza el símil del dinero como el aceite que lubrica el motor de la economía. Desde la escuela marxista, el dinero tiene una concepción más amplia y se analiza desde un nivel más esencial. Para Marx, el dinero es una mercancía y, por tanto, existe una homogeneidad en la esencia de éste y todas las demás mercancías que se comercializan.

\section{a) Esencia de la mercancía}

Las mercancías son todos aquellos productos que están destinados a la comercialización y no al autoconsumo. Un pastel elaborado en casa, para el consumo de sus miembros, no se considera una mercancía, pero sí se considera una mercancía si el pastel fuera para la venta. Esta distinción se debe a que una mercancía posee doble valor: un valor de uso y un valor abstracto.

El valor de uso de la mercancía es aquella utilidad que la persona interesada en ésta le adjudique. Se espera que alguien encuentre algún tipo de utilidad en la mercancía para poder adquirirla. El valor abstracto es aquella homogenización esencial de toda mercancía, es la esencia que permite comparar e intercambiar a las mercancías.

El valor abstracto tiene por magnitud el trabajo socialmente necesario para su elaboración. Esto es así debido a que toda mercancía posee como factor común una cuota de trabajo humano. El trabajo socialmente necesario es aquel trabajo que se establece bajo las eficiencias y medios de producción promedio que imperan en una sociedad. Éste se mide a través de las horas de trabajo.

Marx plantea que existen diferentes tipos de intercambios, desde los más simples como el intercambio entre dos personas y dos mercancías, hasta los más complejos en los que se representan intercambios sociales entre $n$ mercancías y $x$ personas. Es en esta última forma donde nace el dinero como forma de simplificación del comercio.

\section{b) Forma de intercambio simple}

El intercambio simple es aquel en donde existen dos mercancías que se desean intercambiar entre 
dos individuos. En este intercambio, el individuo 1 posee la mercancía A, y el individuo 2 posee la mercancía B. Para hacer esta transacción es necesario que las mercancías tengan un valor abstracto igual, es decir, que el tiempo socialmente requerido para producir A sea igual al tiempo socialmente requerido para producir B. Si esto es así, ambas mercancías se intercambiarán y se podrá decir A vale (o equivale) a B.

Supongamos que el individuo 1 vende y el individuo 2 compra. El individuo que vende tiene el siguiente rótulo: "50 unidades de mercancía A por 1 unidad de mercancía B" (un ejemplo: 50 tomates por un cuaderno). En este simple intercambio suceden dos cosas:

1. Las 50 unidades de mercancía A (50 tomates) adoptan el valor de la mercancía B (1 cuaderno), de lo contrario no pudiera existir este intercambio. Con esto, los tomates buscan homogenizar su valor para poder ser comparables e intercambiables. A este fenómeno se le conoce como la forma relativa del valor.

2. La contraparte mercancía B (1 cuaderno), le presta su forma de valor a los tomates para que éste exprese su valor. Le permite homogenizarse. El cuaderno 'le presta' a los tomates sus términos de valor para que éstos se expresen. A esto se le conoce como una forma equivalencial.

De esta manera ocurre el intercambio simple; $y$, ahora, ya tiene coherencia la frase 50 tomates equivalen a 1 cuaderno. Estas dos formas ocurren en todas las formas de intercambio, no solo en la forma simple.

\section{c) Forma de intercambio total}

Otra forma de intercambio es la forma total. En esta forma existen varias mercancías, las cuales valen lo mismo, por ejemplo: 50 tomates $=1$ cuaderno $=20$ papas $=2$ docenas de lápices, etc. Estas relaciones se vuelven más complejas, pero perfectamente equivalentes, todas equivalen a lo mismo. Bajo esta forma se puede afirmar que todo trabajo humano es equiparable a cualquier trabajo social. Es decir, el valor del trabajo individual tiene su equivalente en el valor del trabajo colectivo.

Debido a lo anterior, en una sociedad más compleja existen dos problemas con el intercambio total: primero, se producen tantos bienes, y de formas tan diversas, que las cadenas son incompletas y podría haber un bien que no es perfectamente equiparable al valor abstracto de todos los demás. Y segundo, existirían bienes que a pesar que su valor es el mismo, sus unidades no podrían dividirse y por tanto no podrían intercambiarse, por ejemplo: 
2 botellas de miel equivalen a 0.75 zapatos. Este intercambio, a pesar de ser perfectamente equivalente, no es funcional, ya que $75 \%$ de un zapato no se puede utilizar.

\section{d) Forma general del valor}

Debido a las limitantes de la forma de intercambio total, surge la forma general del valor con una solución pragmática al intercambio. En esta forma, una mercancía adopta la forma equivalencial, es decir, que se presta como equivalente de todas las demás para que se pueda comercializar. Esta mercancía debe ser divisible (para eliminar lo más que se pueda los problemas de equivalencias) y debe ser duradera, para que no pierda su valor abstracto en el tiempo. No podría ser un helado de vainilla, ya que se derretiría en el tiempo y un helado derretido no posee el mismo valor abstracto que uno bien frío y en un estado consumible.

Se pueden utilizar semillas, cacao, piedras preciosas o metales que funjan como mercancía equivalencial. Esto es algo clave, debe de ser una mercancía, ya que ésta prestará su valor abstracto (tiempo socialmente necesario) para que otras pueden intercambiarse. Una representación de esto podría ser:

\section{Figura 1 Forma general del valor}

\section{Bolígrafos}

10.5 Libras de Papa

2.7 Botellas de Miel

1 Par de Zapatos

1 Libra de Café Oro

Fuente: Elaboración propia.

Todas las mercancías adoptan la forma general de valor en la que expresan su valor de una forma simple y única. Esta forma solo puede existir por un acuerdo social, no de las mercancías, sino de las personas. Todas las personas acordarán expresar el valor de todas sus mercancías (presentes y futuras) en el mismo equivalente, en este caso en libras de café oro.

\section{e) Forma dinero}

La forma general del valor es la forma más cercana a la forma dinero, no tienen diferencias cualitativas entre sí (Montoya, 1999). La transformación entre esta forma y la forma dinero surge cuando una mercancía es creada con el fin de ser mercancía equivalente de todas las demás. 
En el caso de la libra de café oro, ésta tiene un valor de uso diferente al de ser equivalente o dinero. Pero las monedas de oro -que eran acuñadas y moldeadas de forma tal que expresarán valor por sí mismas- ya eran consideradas dinero, porque su función específica era la de fungir como equivalente de todas las demás mercancías.

\section{f) Reflexiones sobre la naturaleza del dinero}

En la actualidad no podemos identificar una mercancía-dinero como tal, sino solo monedas (papeles que no valen lo que representan). Las monedas son simplificaciones o representaciones del dinero. Son una forma en la cual se expresa la mercancía-dinero. Una moneda solo representa que existe otra mercancía que vale lo que ella representa. Tiene el mismo valor abstracto un billete de $\$ 100$ a uno de $\$ 1$, pero representa más el billete de $\$ 100$ que el de uno.

La moneda solo determina una cantidad de mercancía-dinero. Estas nacen por la dificultad de tranzar con la mercancía-dinero, por ejemplo el oro. Este se iba desgastando con el paso del tiempo por lo que iba perdiendo su valor, ya que no representaba la misma cantidad de oro que al principio. Por esta razón surgen las monedas como la forma mediante la cual se resguarda el valor del dinero, es decir, éste no pierde su valor y sin embargo no es necesario tenerlo de mano en mano ni movilizarlo de un lado a otro.

La moneda equivale a una deuda, cada una representa una determinada cantidad de mercancíadinero, es por esto que se puede intercambiar ya que al final representa al dinero. La moneda, como representante del dinero, posee todas sus funciones.

En la actualidad, el dinero como tal no existe; en Bretton Woods se abolió la paridad de las monedas con el dólar. Por lo tanto ya no existe una mercancía que respalde una moneda. Por eso se puede imprimir moneda de manera irrestricta. La moneda y el dinero no es lo mismo. La moneda no representa valor; sin embargo, hoy en día sí. La moneda no tiene una esencia de mercancía, no puede ser valorada como tal; sin embargo, se valora. A esta incongruencia, se le conoce como fetichismo de la mercancía, ya que "se le añade un valor que de suyo no tiene" (Montoya, 1999).

En las transacciones de bienes o servicios (mercado), los cuales son pagados con moneda, no se recuerda o no se conoce que cada moneda equivale, en última instancia, al trabajo social de las demás personas, el cual está representado por una moneda. En el mercado nunca se reconoce que todos los bienes han sido fabricados por alguna persona. En el mercado se 
comercian las mercancías, cuando se olvida que se comercia el trabajo abstracto, que es la única razón por la cual se pueden comparar e intercambiar las mercancías.

\subsection{Moneda alternativa}

La moneda alternativa es una moneda no oficial, voluntaria y coexistente con la moneda oficial de curso. Es una alternativa financiera a la moneda convencional. Las iniciativas de moneda alternativa han sido creadas para lograr un propósito integrador que promueve un desarrollo local sobre la base de valores de cooperación, medio ambientales, sociales y humanos.

La moneda alternativa trata de desfetichizar el dinero. Busca retomar el carácter esencial del mismo, es decir, que sea una mercancía que no posea valor en sí misma, más que el que representa de las demás mercancías. La moneda alternativa no sirve como capital, no sirve para acumular, sino para comercializar. En ésta se reconoce que no tiene valor, y que el único valor es el de las mercancías a las cuales representa.

Esta moneda permite que las personas que sean productoras de bienes posean moneda para intercambiar y comprar bienes que les permitan satisfacer sus necesidades básicas. Cada productor puede poseer moneda, ya que estos poseen un respaldo de la moneda en sus bienes o servicios producidos. Si antes un productor de papas no podía comprar jabón, hoy sí puede, ya que posee papas y éstas son bienes cosechados con trabajo socialmente necesario, el cual es intercambiable por el jabón que fue producido por trabajo socialmente necesario.

En el sistema capitalista, cuando existe una crisis, hay una paradoja comercial, en la cual hay productores que poseen excedentes de sus bienes y necesitan de otros bienes, mientras que otros están con mucha necesidad y sin poder intercambiar dinero por los bienes que necesitan, quedándose así sin poder satisfacer sus necesidades.

Dicho lo anterior, podemos ver un poco la propuesta, citando así a Lietaer (2005) (referido en Collin Harguindeguy, 2007), quien nos dice que "la creación de dinero alternativo permite el establecimiento de intercambios entre productores $y$ consumidores, que tienen un limitado acceso a la moneda corriente, pero que tienen necesidades de consumo y capacidades productivas no aprovechadas y que pueden realizar intercambios entre sí, y requieren un medio para hacerlo".

Ampliando un poco más lo expresado por Lietaer, podemos decir que la moneda alternativa busca facilitar el intercambio para las personas que trabajan y aun así no son capaces de satisfacer plenamente sus necesidades, puesto que el dinero no les alcanza. 


\section{a) Características de la moneda alternativa $^{2}$}

Las monedas alternativas pueden ser utilizadas como un instrumento para crear una alternativa a la economía dominante. Esta alternativa puede responder a los lineamientos que plantea la economía solidaria, pero es necesario precisar que no toda moneda alternativa busca una economía solidaria, ni que toda economía solidaria busca una moneda alternativa. La moneda alternativa y la economía solidaria son un medio y un fin, respectivamente, que se acompañan y trabajan bajo un marco de acción delimitado por el fin, en este caso la economía solidaria.

Según Plasencia \& Orzi (2007) existen ciertas características que la moneda alternativa debe de tener, en orden a ser realmente alternativa e instrumento para una economía alternativa con vetas solidarias. Estas características son:

\section{Desestimula el atesoramiento:}

La moneda alternativa evita el atesoramiento. Busca la eliminación de la función de reserva de valor que tiene el dinero. El atesoramiento fomenta la concentración y la acumulación y, por tanto, la distribución inequitativa. La moneda debe ser un facilitador del intercambio y debe dinamizar. Mientras ésta tenga la capacidad de atesorar y generar valor en el tiempo, se evita el uso o la pérdida de ésta. El uso de la moneda es de beneficio social.

Fue Silvio Gessell, un comerciante argentino-alemán, quien teorizó acerca de la moneda alternativa e ideó una función de oxidación del valor monetario. La oxidación de la moneda indica que la moneda deberá ir perdiendo valor nominal en el transcurso del tiempo, de esta manera la acumulación sería perjudicial a la persona, ya que no podría adquirir bienes (CoIlin, 2007).

\section{Es de carácter comunitario:} Esta característica indica, en esencia, que la moneda debe de nacer y gestionarse por las personas que utilizan esta moneda. Debe de conocerse a fondo por parte de las comunidades bajo las cuales surge. Responderá a intereses identitarios territoriales locales. Una moneda alternativa deberá proteger el espacio de circulación local, fomentando la economía interna en vez de la economía externa.

Debe gestionarse de manera similar que se gestionan las islas, procurando el mayor grado de interacción interna y solo comercializando lo estrictamente fuera del alcance de la misma, buscando la dinamización de comercio mercantil comunitario. 
Por ser de carácter comunitario y alternativo, no debe de ser una moneda excluyente que aleje a las personas de su utilización. Debe incluir y unir pro-sumidores comunales, de manera de crear vínculos de cohesión social entre los mismos.

\section{Transforma la naturaleza de} los intercambios: Transforma a los actores del intercambio, ya que pasan de ser productores y consumidores y se convierten en prosumidores. Este término indica que cada persona es un productor y un consumidor y nunca deja de ser los dos. Es una fusión de términos que responde a la realidad económica amplia.

Debe de transformar las relaciones de intercambio, en donde imperen las relaciones entre productores, como seres humanos, alejándose de las relaciones entre objetos (mercancías) en donde existe un carácter fetichizante y deshumanizante de las relaciones.

Por último, deberá sustituir el intercambio concebido desde una lógica estrictamente mercantil, es decir, que cada productor es a su vez un ser humano con otras esferas de relación y no solo la económica. Debe fomentar el encuentro de individuos en el intercambio.

4. De carácter real: La moneda debe de representar una producción real en la cual fomente solo el dinamismo presente y elimine la especulación que fomenta la abundancia de monedas. En la siguiente tabla se resumen las características que debe de tener la moneda alternativa para que sea considerada como un medio óptimo que responda a la finalidad de economía solidaria.

\section{Tabla 1. Características de la moneda alternativa}

\begin{tabular}{|c|c|c|c|}
\hline Desestimula el atesoramiento & Carácter comunitario & $\begin{array}{l}\text { Transforma la naturaleza del } \\
\text { intercambio }\end{array}$ & Carácter real \\
\hline $\begin{array}{l}\text { - Elimina la función de reserva } \\
\text { de valor del dinero. } \\
\text { - Fomenta la oxidación de la } \\
\text { moneda. }\end{array}$ & $\begin{array}{l}\text { - Auto gestión local. } \\
\text { - Proteger el espacio } \\
\text { territorial. } \\
\text { - Fomenta la inclusión de } \\
\text { pro-sumidores } \\
\text { - Dinamiza el comercio } \\
\text { local. }\end{array}$ & $\begin{array}{l}\text { - Transformación de } \\
\text { actores. De productores } \\
\text { y consumidores a pro- } \\
\text { sumidores. } \\
\text { - Transforma las relaciones de } \\
\text { intercambio. } \\
\text { - Transforma la lógica de } \\
\text { intercambio. }\end{array}$ & $\begin{array}{l}\text { - Se basa en una } \\
\text { economía real. }\end{array}$ \\
\hline
\end{tabular}

Fuente: Elaboración propia con base en Plasencia \& Orzi (2007) pp. 36-39 
Para la presente investigación se recolectó la información de 96 productores, 49 de ellos provenientes de la RXT y los 47 restantes provenían de otros productores en el municipio de Suchitoto. La razón de esta distribución fue la necesidad de tener un grupo experimental (Productores de la RXT) y otro grupo control.

Se determinó una muestra estratificada del municipio de Suchitoto. En el municipio, el $70 \%$ de las personas vive en el territorio rural y el $30 \%$ en el casco urbano. En la investigación, por dificultades de transporte y cooperación, no se pudo representar exactamente estas proporciones. De las 96 encuestas, el 54\% corresponde al sector rural y el $46 \%$ al sector urbano. Las variables principales en esta investigación son: el uso de la moneda alternativa como medio para el intercambio de bienes y servicios, y las nociones de inclusión, respeto, solidaridad y equidad que promueve la economía solidaria.

Para evaluar estas dos variables se optó por una encuesta de opciones múltiple. Las preguntas fueron realizadas con base en escenarios hipotéticos. Los usuarios tenían cinco respuestas, ponderadas de uno a cinco. La escala de valores para cada respuesta está plasmada en la Tabla 2.

Tabla 2

Ponderación de variables de la encuesta realizada*

\begin{tabular}{|c|l|l|}
\hline Escalas & \multicolumn{1}{|c|}{ Economía solidaria } & \multicolumn{1}{|c|}{ Moneda alternativa } \\
\hline 1 & $\begin{array}{l}\text { Actitud que refleja un comportamiento } \\
\text { egoísta u opuesto a los principios de } \\
\text { economía solidaria }\end{array}$ & $\begin{array}{l}\text { Actitud que refleja una actitud incompati- } \\
\text { ble a la moneda alternativa (UDIS) }\end{array}$ \\
\hline 2 & $\begin{array}{l}\text { Actitud que refleja un comportamiento } \\
\text { individualista }\end{array}$ & $\begin{array}{l}\text { Actitud que refleja una actitud negativa a } \\
\text { la moneda alternativa (UDIS) }\end{array}$ \\
\hline 3 & $\begin{array}{l}\text { Actitud que refleja un comportamiento } \\
\text { de satisfacción de necesidades básicas, } \\
\text { pero en sentido individual }\end{array}$ & $\begin{array}{l}\text { Actitud que refleja una actitud neutra a la } \\
\text { moneda alternativa (UDIS) }\end{array}$ \\
\hline 4 & $\begin{array}{l}\text { Actitud que refleja un comportamiento } \\
\text { solidario }\end{array}$ & $\begin{array}{l}\text { Actitud que refleja una actitud favorable } \\
\text { a la moneda alternativa (UDIS) }\end{array}$ \\
\hline 5 & $\begin{array}{l}\text { Actitud que refleja un comportamiento } \\
\text { muy solidario }\end{array}$ & $\begin{array}{l}\text { Actitud que refleja una actitud muy fa- } \\
\text { vorable a la moneda alternativa (UDIS) }\end{array}$ \\
\hline
\end{tabular}

* Las escalas fueron elaboradas bajo el juicio del equipo investigador.

Fuente: Elaboración propia. 
Se realizaron 12 preguntas referentes a la economía solidaria, que buscaban retratar la empatía en las actividades laborales, la conciencia medio ambiental, la preferencia de relación laboral, modos de consumo y gasto, nociones de asociatividad social y equidad de género. También se realizaron 14 preguntas referentes a la moneda alternativa, que buscaban retratar y reflejar la frecuencia de utilización de la moneda, identidad, asociatividad productiva, confianza en el UDIS, preferencias de compra y venta, preferencias monetarias.

El resultado obtenido se ponderó y se obtuvo un promedio simple. Este promedio simple fue considerado como: ES_AVG (índice de comportamiento económico solidario) y MA_AVG (índice de utilización y actitud favorable a la moneda alternativa). Cada miembro de la encuesta obtuvo un índice de economía solidaria y moneda alternativa.

Una vez obtenidos los índices, se corrió una segmentación del estilo two headed cluster, utilizando el software estadístico SPSS versión 20. Con esta segmentación se pretende evaluar si existen centroides en ES_AVG y MA_AVG dentro de los habitantes de Suchitoto y de la RXT. Los centroides son medias concentradas a las que se asocian las medias observadas de los habitantes. Existe un indicador de cohesión y separación de las medias que toma valores entre 0 y 1 . El valor de 0 representa a un segmento disperso, por lo que los resultados que estén presentes no son representativos, caso contrario si toma el valor de 1 . Para la presente investigación se obtuvieron los siguientes resultados:

Figura 2

Indicador de cohesión y separación de los segmentos

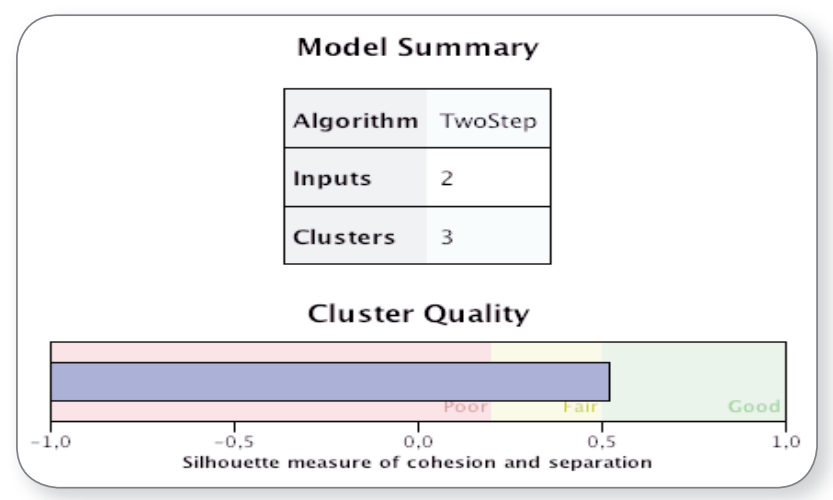

Fuente: Elaboración propia usando el paquete estadístico SPSS versión 20. 
La Figura 2 muestra que existe una calidad aceptable en los segmentos creados. Con las dos variables investigadas se formaron tres segmentos. Los resultados fueron evaluados a nivel demográfico para analizar el tipo de habitantes que conformaban cada segmento y poder concluir con respecto al efecto de la moneda alternativa en el municipio de Suchitoto y la RXT.

\section{Resultados}

Se realizaron 110 encuestas, de las cuales 96 fueron completadas correctamente. La distribución de la muestra fue de 49 usuarios de la RXT y 47 productores no afiliados a la red. Se recolectaron 52 encuestas rurales y 44 encuestas urbanas.

La producción de los usuarios de la RXT es eminentemente agrícola y de subsistencia. El 59\% de la producción está constituida por alimentos, hortalizas, maíz y frijol. Existe solo un productor que ofrece abono y otro que ofrece servicios de transporte. Servicios y productos varios constituyen un $10 \%$ de la producción mientras que la artesanía está conformada por el $17 \%$ de los usuarios de la muestra obtenida de la RXT.

\section{Figura 3}

\section{Producción real de la RXT en Suchitoto}

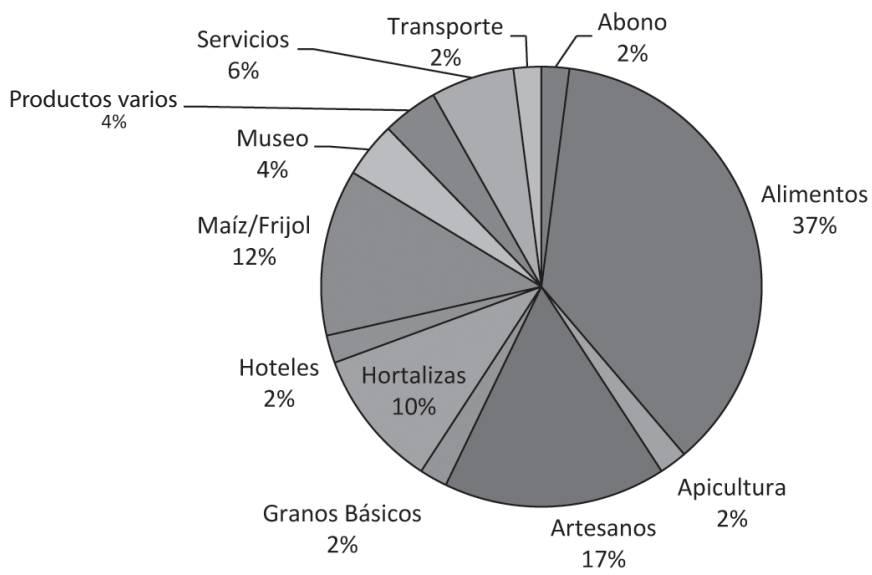

Fuente: Elaboración propia

En los niveles de solidaridad, fueron: ES_AVG $=3.76$ y MA_AVG las medias del total de la muestra $=2.85$ con una valores máximos 
de 5 y valores mínimos de 1 ambos indicadores. La desviación estándar fue: $E S \_A V G=0.435$ y MA_AVG $=0.790$.
Los usuarios de la RXT muestran niveles más altos de ES_AVG y MA_AVG además de desviaciones estándar menos amplias.

Tabla 3

ES_AVG y MA_AVG por grupo de estudio

\begin{tabular}{|l|c|c|}
\hline \multicolumn{3}{|c|}{ Valores reales } \\
\hline & RXT & OTROS PROD. \\
\hline ES_AVG & 3.810 & 3.698 \\
MA_AVG & 2.851 & 2.852 \\
\hline
\end{tabular}

\begin{tabular}{|l|c|c|}
\hline \multicolumn{3}{|c|}{ Desv. estándar } \\
\hline & RXT & OTROS PROD. \\
\hline ES_AVG & 0.324 & 0.449 \\
MA_AVG & 0.694 & 0.926 \\
\hline
\end{tabular}

Fuente: Elaboración propia

A nivel de género, las mujeres presentan un mayor nivel de solidaridad y de utilización de la moneda alternativa. También son las que muestran una distribución estándar menos amplia que los hombres.

\section{Tabla 4}

ES_AVG y MA_AVG por género

\begin{tabular}{|l|c|c|}
\hline \multicolumn{3}{|c|}{ Valores reales } \\
\hline & MUJER & HOMBRE \\
\hline ES_AVG & 3.781 & 3.723 \\
MA_AVG & 2.945 & 2.734 \\
\hline
\end{tabular}

\begin{tabular}{|l|c|c|}
\hline \multicolumn{3}{|c|}{ Desv. estándar } \\
\hline & MUJER & HOMBRE \\
\hline ES_AVG & 0.338 & 0.460 \\
MA_AVG & 0.745 & 0.867 \\
\hline
\end{tabular}

Fuente: Elaboración propia

La confianza en el UDIS es un factor que permite determinar si esta moneda alternativa será aceptada en el tiempo y permitirá seguir siendo medio de pago (presente y futuro). El $72.9 \%$ de los usuarios de la RXT confían en el UDIS en contraste con el $17.5 \%$ de Otros Productores que confían en el UDIS.
Los usuarios que dicen poseer confianza en el UDIS presentan un nivel de solidaridad mayor a los que dicen que no confían en el UDIS. La variación estándar es menor en los usuarios que no confían en el UDIS teniendo valores más altos y menos volátiles. 
Tabla 5

ES_AVG y MA_AVG por confianza en UDIS

\begin{tabular}{|l|c|c|}
\hline \multicolumn{3}{|c|}{ Valores reales } \\
\hline & NO CONFÍA & Sí CONFíA \\
\hline ES_AVG & 3.680 & 3.818 \\
MA_AVG & 2.480 & 3.188 \\
\hline
\end{tabular}

\begin{tabular}{|l|c|c|}
\hline \multicolumn{3}{|c|}{ Desv. estándar } \\
\hline & NO CONFÍA & Sí CONFíA \\
\hline ES_AVG & 0.417 & 0.334 \\
MA_AVG & 0.684 & 0.490 \\
\hline
\end{tabular}

Fuente: Elaboración propia

En el análisis de segmentos, el modelo creó 3 segmentos basados en las variables ES_AVG y MA_AVG.
La importancia de estas variables es significativa y ayuda de manera fiable a generar los segmentos.

\section{Figura 4. Resumen de análisis de segmento}

\begin{tabular}{|c|c|c|c|}
\hline & & \multicolumn{2}{|c|}{$\begin{array}{c}\text { Input (Predictor) Importance } \\
\square 1,0 \square 0,8 \square 0,6 \square 0,4 \square 0,2 \square 0,0\end{array}$} \\
\hline Cluster & 1 & 3 & 2 \\
\hline Label & SOLIDARIOS & PRO UDIS & TRADICIONALES \\
\hline Description & $\begin{array}{c}\text { Usuarios con alto } \\
\text { nivel de solidaridad } \\
\text { pero con actitud un } \\
\text { poco negativa con } \\
\text { respecto a la } \\
\text { Moneda Alternativa }\end{array}$ & $\begin{array}{c}\text { Son los usuarios } \\
\text { que presentan la } \\
\text { mejor disposición a } \\
\text { la moneda } \\
\text { alternativa. }\end{array}$ & $\begin{array}{l}\text { Son el usuario } \\
\text { esperado, aquel } \\
\text { que no es tan } \\
\text { solidario y que } \\
\text { presenta la peor } \\
\text { disposición a la } \\
\text { moneda alternativa. }\end{array}$ \\
\hline Size & $\mid \begin{array}{r}39,6 \% \\
(38)\end{array}$ & $\left|\begin{array}{r}35,4 \% \\
(34)\end{array}\right|$ & $\begin{array}{r}25,0 \% \\
(24)\end{array}$ \\
\hline \multirow[t]{2}{*}{ Inputs } & $\begin{array}{c}\text { MA_AVG } \\
2,62\end{array}$ & $\underset{3,52}{\text { MA_AVG }}$ & $\begin{array}{c}\text { MA_AVG } \\
2,26\end{array}$ \\
\hline & $\begin{array}{c}\text { ES_AVG } \\
4,08\end{array}$ & $\underset{3,73}{\text { ES_AVG }}$ & $\begin{array}{c}\text { ES_AVG } \\
3,29\end{array}$ \\
\hline
\end{tabular}

Fuente: Elaboración propia usando el paquete estadístico SPSS

Los tres segmentos son: SOLIDARIOS, PRO UDIS y TRADICIONALES. El segmento TRADICIO-
NALES es el segmento control ya que muestra los menores niveles de percepción de solidaridad y 
del uso de la moneda alternativa (MA_AVG $=2.26$, ES_AVG $=3.29$ ). El Segmento PRO UDIS son las personas cuyo percepción sobre el uso de la moneda alternativa es la más alta y favorable; son usuarios que utilizan seguido los UDIS, que confían en ellos y que aprovechan las facilidades transaccionales que esta moneda provee (MA_AVG = 3.52). Por último, están el segmento
SOLIDARIOS. Estos usuarios son los que destacan en el índice de solidaridad mostrando mayor percepción y conocimiento de los principios de economía solidaria (ES_AVG = 4.08). Estos usuarios no necesariamente son los que más utilizan la moneda alternativa. Su MA_AVG es ligeramente mayor que los TRADICIONALES (MA_AVG = 2.62).

\section{Figura 5. Distribución de medias para conglomerados en base ES_AVG y MA_AVG}

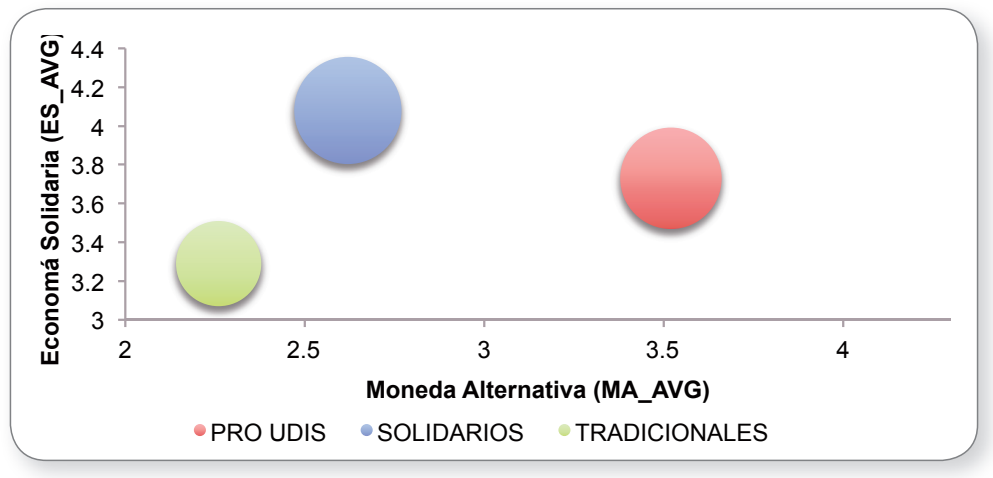

Fuente: Elaboración propia

Evaluando demográficamente cada segmento, encontramos que existen productores tanto de la RXT y de Otros Productores en todos los segmentos. El Segmento SOLIDARIOS está conformado por 38 personas, de las cuales el $55 \%$ es parte de la RXT y $45 \%$ es parte de los Otros Productores. El Segmento PRO UDIS contiene 34 personas, de las cuales el $55 \%$ es parte de la RXT y el $45 \%$ parte de los Otros productores. El Segmento TRADICIONALES contiene 24 personas, el $37.5 \%$ forma parte de la RXT y el $62.5 \%$ restante es parte de Otros Productores. En todos los segmentos encontramos hombres y mujeres que son del área rural o del área urbana. No se encontró ningún grupo demográfico que representara un segmento por sí solo.

En todos los grupos, la mayor parte de encuestados proviene de personas con edades mayores a los 31 años, siendo los jóvenes de 30 años o menos el $20 \%$ de los encuestados. 

y MA_AVG

\begin{tabular}{|c|c|c|c|c|c|c|c|}
\hline & \multicolumn{2}{|c|}{ Origen } & \multicolumn{2}{|c|}{ Genero } & \multicolumn{2}{|c|}{ Territorio } \\
\hline & & RXT & $\begin{array}{c}\text { Otros } \\
\text { Productores }\end{array}$ & FEMENINO & MASCULINO & RURAL & URBANO \\
\hline & & Count & Count & Count & Count & Count & Count \\
\hline TwoStep Cluster & Outlier Cluster & 0 & 0 & 0 & 0 & 0 & 0 \\
\hline Number & SOLIDARIOS & 21 & 17 & 21 & 16 & 20 & 18 \\
\hline & TRADICIONALES & 9 & 15 & 9 & 15 & 13 & 11 \\
\hline & PRO UDIS & 19 & 25 & 23 & 11 & 20 & 14 \\
\hline
\end{tabular}

\begin{tabular}{|c|c|c|c|c|c|c|}
\hline & \multicolumn{5}{|c|}{ Rango_Edad } \\
\hline & & $0-20$ & 21-30 años & $31-40$ años & 41-50 años & $51+$ años \\
\hline & & Count & Count & Count & Count & Count \\
\hline \multirow{4}{*}{$\begin{array}{l}\text { TwoStep Cluster } \\
\text { Number }\end{array}$} & \multirow{4}{*}{$\begin{array}{r}\text { Outlier Cluster } \\
\text { SOLIDARIOS } \\
\text { TRADICIONALES } \\
\text { PRO UDIS } \\
\end{array}$} & 0 & 0 & 0 & 0 & 0 \\
\hline & & 1 & 8 & 12 & 7 & 7 \\
\hline & & 0 & 7 & 0 & 6 & 11 \\
\hline & & 1 & 3 & 9 & 14 & 7 \\
\hline
\end{tabular}

Fuente: Elaboración propia utilizando el paquete estadístico SPSS

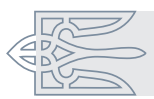

Evaluando la estructura económica de los miembros de la RXT, encontramos que $59 \%$ de los productores producen bienes similares, bienes de alimento y cultivos de maíz y/o frijol. Esto hace que la oferta de los usuarios sea bastante parecida. El uso de una moneda alternativa no será muy efectivo debido a que no existen relaciones económicas complementarias. Todos producen lo mismo y no genera ningún beneficio en la satisfacción de las necesidades básicas comercializar con los mismos productos. La RXT posee un reto en diversificar su oferta, de lo contrario, a pesar de que exista la moneda alternativa, los usuarios no podrán intercambiar bienes ya que no generaría ningún valor de uso al comprador.

\section{Conclusiones}

Existen diferencias en los índices de ES_AVG y MA_AVG entre bloques demográficos. En promedio, los miembros de la RXT poseen un mayor índice de solidaridad que los Otros Productores. En cuanto a la moneda alternativa, no existe diferencia entre los índices, aunque la dispersión de datos es mayor en los Otros Productores. Esto quiere decir que existen usuarios que aceptan el UDIS y tienen una alta noción de moneda alternativa y usuarios que carecen de la misma. Esto se viene a reforzar, al evaluar los segmentos y encontrar usuarios PRO UDIS que son parte de los Otros Productores.

Esta heterogeneidad nos refleja que el entorno y las relaciones de pertenencia a una red de produc- 
tores no asegura la aceptación de principios y valores solidarios, ya que existen personas de la RXT que conforman el segmento de personas TRADICIONALES. También nos muestra que la moneda alternativa, como herramienta de la economía solidaria, no genera mayores niveles de conciencia y aceptación de principios solidarios. Las personas que más utilizan o aceptan la moneda alternativa no son las personas que muestran los mayores niveles de solidaridad. El uso de la moneda alternativa, a pesar de que sí fomente interrelaciones de intercambio entre miembros de una comunidad, no genera un efecto diferenciador en percepción de solidaridad. Las personas utilizan la moneda como un facilitador para satisfacer sus necesidades básicas, no por un acto de solidaridad y empatía con los demás.

Un mayor índice y noción de conceptos de economía solidaria no viene ni de la afiliación a una red o al uso de una moneda, viene de la realidad en la que las personas estén inmersas, la cual los hace sensibilizarse hacia los demás. En una encuesta realizada a una mujer en el cantón San Antonio, se le preguntó si ella vendería toda su mercancía a una sola persona por el precio más alto que ella pidiera. Una respuesta poco solidaria fuera decir que sí, pero ella contestó que no, ella produce y vende cuajada y tortillas. Lo más impresionante fue su racionalización de porqué no lo haría: "cómo podría yo vender- le todo a una sola persona si hay tantas que necesitan comer, acá me vienen pidiéndome tortillas fiadas [a plazo] yo prefiero regalárselas, usted no sabe que es vivir con hambre, las personas acá necesitan de toda la ayuda que uno les pueda dar". Esta frase resume la solidaridad, ella sí era parte de la RXT, pero no fue la única que respondió de esta manera.

La solidaridad no es algo teóri$\mathrm{co}$, es algo vivencial. Las personas que menos tienen son las más unidas, ya que no podrían soportar una vida de miserias ellos solos y ésta es la mejor escuela que tienen: no una red de productores o una moneda diferente y local, es su empatía por las necesidades y las vivencias de los demás.

Como resultado final, la moneda alternativa no es un potenciador directo de la economía solidaria, tampoco lo es el afiliarse a una red de productores, lo que realmente transforma una sociedad a una sociedad solidaria es la empatía entre las personas, las redes que éstas puedan hacer entre sí, conocer de primera mano a la comunidad. La moneda alternativa posee un carácter unificador ya que las personas recurrirán a otras personas que comercien con la moneda, y a la larga esto podría hacer un gran tejido social; sin embargo, debe de ir de la mano con experiencias como la de la señora que vendía cuajada. La solidaridad es un componente 
muy complejo que no puede ser abordado solo desde la economía o del uso de un instrumento finan- ciero diferente. La solidaridad es un cambio de paradigma, una utopía por construir.

\section{Bibliografía}

os Cardona, E. (2012) Entrevista con Promotor UDIS en Suchitoto. Suchitoto.

os Collin Harguindeguy, L. (2007) Experiencias en torno al dinero alternativo, fortalezas y debilidades. Pasos, 11 (132), 11-22.

os Dornbusch, R., Fischer, S., \& Startz, R. (2008) Macroeconomía (10th ed.). McGraw-Hill/Interamericana Editores.

os Godelier, M. (1996) El enigma del don Dinero, regalos, objetos santos. Barcelona. Paidós Ibérica, p. 1.

os Marx, K. (1999) El Capital. México D.F.: Fondo de Cultura Económica.

os Montoya, A. (1999) Economía crítica. San Salvador: Editores Críticos.

os Plasencia, A., \& Orzi, R. (2007) Moneda Social y Mercados Solidarios (Valeria Gorza). Buenos Aires: Ediciones CICCUS.

os Razeto, L. (1993) Los caminos de la economía solidaria. Ediciones Vivarium. Disponible en: http://lacoperacha.org.mx/documentos/coperachaeconomia-solidaria-razeto.pdf

os UCA (2005) Economía solidaria: Grupo Bajo Lempa Occidental. San Salvador: Talleres Gráficos UCA.

\section{Notas}

1 Este trabajo fue realizado con el apoyo de Fundación REDES y con el especial aporte de Enrique Cardona (2012), promotor de la RXT y del UDIS.

2 Literal basado en Moneda social y mercados solidarios. Plasencia \& Orzi, 2007. 